\title{
Surgical treatment of temporal lobe epilepsy: clinical, radiological, and histopathological findings in 178 patients
}

Department of Neurosurgery J Zentner E Behrens M G Campos J Schramm

Department of Epileptology A Hufnagel C E Elger

Department of Neuroradiology B Ostertun L Solymosi

Institute of Neuropathology, University of Bonn, Germany $\mathrm{H} \mathrm{K}$ Wolf O D Wiestler

Correspondence to: Dr Josef Zentner Department of Neurosurgery, University of Bonn, Sigmund-FreudStraße 25, 53105 Bonn, Germany.

Received 15 June 1994 and in revised form 10 November 1994

Josef Zentner, Andreas Hufnagel, Helmut K Wolf, Burkard Ostertun, Elga Behrens, Manuel G Campos, Laszlo Solymosi, Christian E Elger, Otmar D Wiestler, Johannes Schramm

\begin{abstract}
The surgical treatment of pharmacoresistant temporal lobe epilepsy is increasing rapidly. The correlation of preoperative MRI, histopathological findings, and postoperative seizure control is reported for 178 patients with chronic medically intractable temporal lobe epilepsy who were operated on between November 1987 and January 1993. Histopathologically there were distinct structural abnormalities in $97 \cdot 2 \%$ of the surgical specimens. Signal abnormalities on MRI were present in $98 \cdot 7 \%$ of patients with neoplastic lesions $(n=79), 76.6 \%$ of patients with non-neoplastic focal lesions $(n=55)$, and $69.2 \%$ of patients with Ammon's horn sclerosis $(n=39)$. Overall, structural abnormalities were detected by MRI in $82.7 \%$ of all patients. The mean postoperative follow up period was three years. Some $92 \%$ of the patients benefited from surgery: 103 patients $(61 \cdot 7 \%)$ were seizure free, $26(15.5 \%)$ had no more than two seizures a year, and $24(14 \cdot 4 \%)$ showed a reduction of seizure frequency of at least

Temporal lobe epilepsy is the most common form of epilepsy, with a prevalence of around $0.1 \%$ in the general population. ${ }^{1}$ Despite optimal pharmacotherapy, about $30 \%$ of the patients do not become seizure free. ${ }^{2}$ Recently, there has been increased interest in the relation between structural lesions and epileptic seizures. Abnormalities that are often found in association with intractable seizures include low grade tumours, ${ }^{3-13}$ non-tumorous disorders, ${ }^{14-19}$ and Ammon's horn sclerosis. ${ }^{20-24}$ Moreover, the presence of a "dual pathology"-that is, a focal lesion in association with Ammon's horn sclerosis-has been found in many cases. ${ }^{25-27}$ Magnetic resonance imaging has been found to be valuable for both identification and localisation of various lesions. ${ }^{28-38}$ Most recent reports on temporal lobe epilepsy have been limited to small numbers of patients and predominantly consider specific aspects. Here we provide a comprehensive report on 178 patients with a mean follow up period of three years. The relation between clinical, radiological, and histopathological findings and postoperative seizure control is presented in detail.
\end{abstract} $75 \%$. Fourteen patients $(8 \cdot 4 \%)$ had a $<75 \%$ reduction of seizure frequency. The percentage of patients who were completely free of seizures after operation was $68.5 \%$ for patients with neoplastic lesions, $\mathbf{6 6 . 7 \%}$ for Ammon's horn sclerosis, and $54.0 \%$ for patients with non-neoplastic focal lesions. By contrast, none of the patients in whom histopathological findings were normal became seizure free postoperatively. The data show that the presence of focal lesions or Ammon's horn sclerosis as determined by histopathological examination is associated with improved postoperative seizure control compared with patients without specific pathological findings. Brain MRI was very sensitive in detecting neoplasms; however, its sensitivity and specificity were limited with respect to non-neoplastic focal lesions and Ammon's horn sclerosis. Improvement of imaging techniques may provide a more precise definition of structural lesions in these cases and facilitate limited surgical resections of the epileptogenic area rather than standardised anatomical resections.

(F Neurol Neurosurg Psychiatry 1995;58:666-673)

Keywords: epilepsy; temporal lobe; magnetic resonance imaging; histopathology

\section{Patients and methods}

Between November 1977 and January 1993 227 patients underwent surgical treatment for temporal lobe epilepsy at the Department of Neurosurgery, University of Bonn. The patients had a well documented chronic and medically intractable epilepsy lasting for a minimum of two years. For all patients adequate periods of treatment with at least two first line anticonvulsant agents such as carbamazepine, phenytoin, phenobarbitone, or valproic acid were required before referral for presurgical evaluation. Histopathological evaluation of surgical specimens showed uncertain findings in 49 cases. These specimens did not show focal lesions; however, they were not appropriate to allow definite conclusions as to the presence or absence of Ammon's horn sclerosis. Thus these 49 patients were omitted, leaving 178 patients in this series.

All patients underwent continuous video EEG monitoring by cable telemetry with scalp and sphenoidal electrodes. If the site of the seizure origin remained undetermined, bilateral subdural strip electrodes and-more recently-additional stereotactic depth electrodes were used to identify the epileptogenic area. Extraoperative electrocorticographic studies were done in 74 of the 178 patients $(41 \cdot 8 \%)$. Of these, 61 patients had subdural 
electrodes only, and 13 had both subdural and depth electrodes. The site and extent of the resection were based mainly on the ictal and interictal EEG pattern and-if presenton the site of a localised structural lesion as determined by MRI. Other information was used to confirm the location of the epileptogenic area and to assess the risks and prognosis of resecting this. The information included a detailed evaluation of seizure history and semiology, neuropsychological studies, psychiatric evaluation, and intracarotid amylobarbitone testing in most cases. Studies with single proton emission computed tomography (SPECT) have been performed in a subgroup of patients. A detailed analysis will be published elsewhere. ${ }^{39}$

In all, $168 \mathrm{MRI}$ examinations were available for review. Of these, about $50 \%$ were performed at the University of Bonn Medical Centre. The rest were done at various other institutions. At our institution, MRI was carried out with a 1.5 Tesla unit (Philips Gyroscan S15) with at least sagittal T1 weighted images (TR/TE/slice thickness = $500-600 \mathrm{~ms} / 15-25 \mathrm{~ms} / 8-10 \mathrm{~mm}$ ) and axial proton density weighted and T2 weighted images (TR/TE/slice-thickness $=2000-2500$ $\mathrm{ms} / 20-30$ and $80-120 \mathrm{~ms} / 6-8 \mathrm{~mm})$. Usually, spin echo scans were performed. T2 weighted gradient echo scans were done only rarely. If a tumour was suspected, additional coronal and axial $\mathrm{T} 1$ weighted images with and without gadolinium-DTPA were acquired with similar parameters. If there was prior evidence for a temporal focal lesion, axial images were often acquired with a modified angulation parallel to the long axis of the temporal lobe-that is, about $25^{\circ}$ off the orbitomeatal line.

Examinations with MRI from other institutions included a wide range of technical variations. Employing systems of various manufacturers and field strengths, slices were generally 1-2 mm thicker than those obtained at our institution, whereas acquisition of one $\mathrm{T} 1$ weighted and one $\mathrm{T} 2$ weighted scan in two different planes was standard. Some-

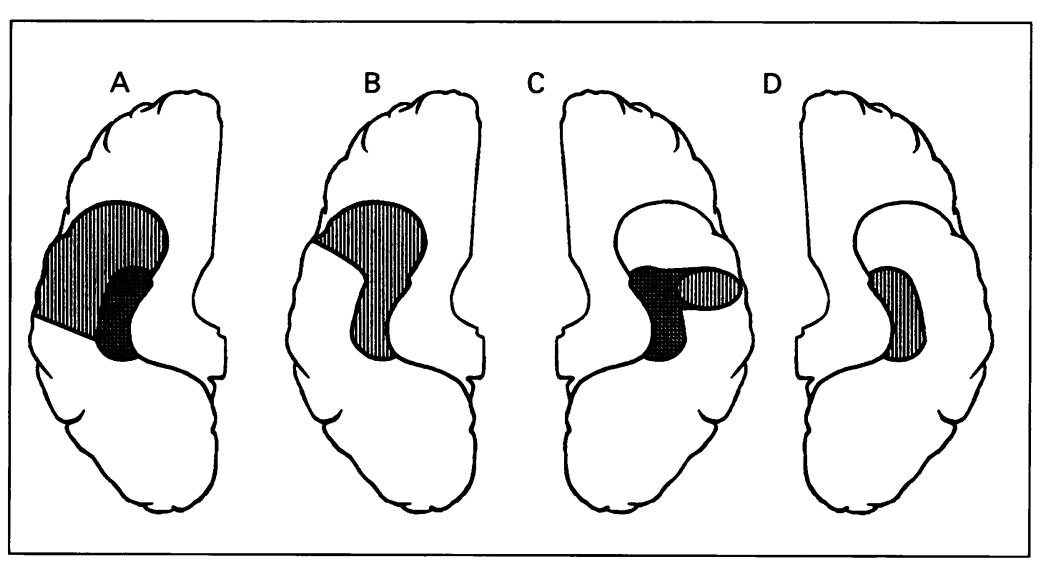

Figure 1 Schematic presentation of different resective procedures used for this series: standard anterior temporal lobectomy with and without hippocampectomy $(A)$; "key-hole" resection with hippocampectomy (B); extended lesionectomy with and without hippocampectomy $(C)$; and selective amygdalohippocampectomy (D). times, no proton density weighted images had been performed. The modified "temporal" orientation for axial images was not used in these examinations. The differences in imaging techniques reflect the fact that there is no standardised protocol for the examination of patients with temporal lobe epilepsy.

All preoperative MRI studies were retrospectively evaluated by a neuroradiologist with no other information available. Findings on MRI were classified as follows: tumour, non-tumorous lesion, signal abnormalities of "uncertain" significance, Ammon's horn sclerosis, and no detectable abnormality. The term "uncertain" was used with respect to the interpretation of imaging studies if the findings were not conclusive due to insufficient image quality, questionable partial volume effects, or the lack of appropriate sequences or sectional planes. The diagnosis of Ammon's horn sclerosis was based on the following criteria: increased signal on T2 weighted images or temporomesial atrophy with an enlarged temporal horn of the lateral ventricle. Volumetric measurements of hippocampal size were not performed.

The following surgical procedures were performed: anterior temporal lobectomy (standard or "keyhole") with hippocampectomy ( $\mathrm{n}=144)$, anterior temporal lobectomy without hippocampectomy $(n=8)$, extended lesionectomy with hippocampectomy $(n=9)$, extended lesionectomy without hippocampectomy $(n=15)$, and selective amygdalohippocampectomy $(n=2)$ (fig 1$)$. Thirteen patients in whom anterior temporal lobectomy with hippocampectomy was performed had been operated on previously at other institutions for tumours; however, their seizure outcome had not been improved.

All operations were performed under general anaesthesia without intraoperative electrocorticography. In every case, complete removal of a radiologically identified lesion was intended. A standard anterior temporal lobectomy consisted of a $4.5 \mathrm{~cm}$ (non-dominant hemisphere) and $4 \mathrm{~cm}$ (dominant hemisphere) resection of the superior and middle temporal gyri and a $5.5 \mathrm{~cm}$ (non-dominant hemisphere) and $5 \mathrm{~cm}$ (dominant hemisphere) resection of the inferior temporal gyrus. This was followed by removal of the amygdala, the parahippocampal uncus, and total resection of the hippocampus and parahippocampal gyrus. If there was adequate memory performance of the non-operated temporal lobe as evaluated by neuropsychometric and intracarotidal amylobarbitone testing, the anterior 3 to $3.5 \mathrm{~cm}$ of the parahippocampal gyrus and hippocampus were resected.

In cases with insufficient contralateral memory performance, resection of the hippocampus was limited to $1-2 \mathrm{~cm}$, or the hippocampus was preserved completely. Extended lesionectomy was performed by an anterolateral or posterolateral approach depending on the location of the lesion. In some patients, these procedures were combined with amygdalohippocampectomy. Selective amygdalohippocampectomy was 
performed by the trans-sylvian route as described by Wieser and Yasargil. ${ }^{40}$

All glass slides of operative specimens were reviewed by two neuropathologists. Sections stained with haematoxylin and eosin were available from all cases. In most specimens there were also slides with Nissl stains and combined haematoxylin-eosin-luxol-fast blue stains available. In selected cases additional special stains (elastic van Gieson, reticulin, Bodian) were used. In all tumour cases some or all of the following immunohistochemical reactions were carried out: glial fibrillary acid protein, synaptophysin, neurofilament protein, neuron specific enolase, and S 100 protein. Tumours were classified according to the revised World Health Organisation classification for tumours of the nervous system. ${ }^{40}$ Histological findings were divided into four groups: neoplasm, non-neoplastic focal lesion, Ammon's horn sclerosis, and absence of specific histopathological alterations.

Follow up information, available from 167 patients, was based on regular outpatient visits to hospital at three to 12 month intervals. Postoperative observation time ranged from 12 to 72 months (mean three years). With respect to the postoperative seizure state, patients were assigned to four different outcome classes as described by Engel et $a l^{30}$ : (a) seizure free or only auras since surgery, (b) rare seizures ( $\leqslant 2$ per year), (c) reduction of seizure frequency $\geqslant 75 \%$, and (d) unchanged $(<75 \%$ reduction of seizure frequency). Student's $t$ test was used for statistical comparison of continuous variables if the distribution was normal, and Wilcoxon's test if it was not. Discrete variables were compared by cross tabulation.

\section{Results}

CLINICAL FINDINGS

There were 82 male and 96 female patients with ages ranging from 3 to 64 years and a mean age of 27.7 years. All patients had complex partial seizures, 78 of them with secondary seizure generalisation.

Patients' ages at onset of seizures ranged between 1 and 45 (mean 15.9) years.

Table 1 Main histopathological diagnoses in 178 specimens from patients with temporal lobe epilepsy

\begin{tabular}{lc}
\hline Histopathological diagnosis & $\begin{array}{l}\text { Patients } \\
\text { No (\%) }\end{array}$ \\
\hline Neoplasm & $79(44 \cdot 4)$ \\
Non-neoplastic lesion & \\
Glioneuronal hamartia & $19(10 \cdot 7)$ \\
Glioneuronal hamartoma & $5(2 \cdot 8)$ \\
Vascular malformation & $14(7 \cdot 9)$ \\
Old necrosis & $3(1 \cdot 7)$ \\
Abundant neurons in white matter & $3(1 \cdot 7)$ \\
Chronic encephalitis & $2(1 \cdot 1)$ \\
Other & $9(5 \cdot 0)$ \\
Ammon's horn sclerosis & $39(21 \cdot 9)$ \\
Normal & $5(2 \cdot 8)$ \\
Total & $178(100 \cdot 0)$ \\
\hline In some specimens more than one pathological abnormality \\
was present. Only 72 specimens were sufficiently preserved to \\
permit an evaluation as to the presence of Ammon's horn \\
sclerosis. The incidence of Ammon's horn sclerosis in this \\
subgroup was $72 \cdot 2 \%$.
\end{tabular}

Duration of epilepsy varied between two and 52 years with a mean of 12.2 years. Patients' mean age at surgery was 26.2 years with neoplastic lesions, 26.5 years with non-neoplastic focal lesions, and 29.2 years with Ammon's horn sclerosis. Mean age at onset of seizures was 14.2 years in patients with neoplastic lesions, 14.7 years in patients with non-neoplastic focal lesions, and 17.9 years in patients with Ammon's horn sclerosis. As determined by Student's $t$ test the patients' ages at the time of surgery and the ages at the first onset of seizures were significantly lower in patients with focal lesions than in those without focal lesions $(P<0.01)$. There was considerable overlap between the two groups. No statistically significant differences were present for duration of seizures between any of these groups.

\section{HISTOPATHOLOGICAL FINDINGS}

Table 1 gives the results of histopathological examination of the specimens obtained at operation. In 106 patients $(56.7 \%)$, a definite histopathological statement as to the presence or absence of Ammon's horn sclerosis was impossible. In some cases, segmental neuronal loss and gliosis were obscured by infiltrating tumour or inflammation. More often, however, the portion of the hippocampal formation that was actually submitted for pathological evaluation consisted only of small tissue fragments that did not permit a proper orientation during embedding and a reliable identification of the different segments of Ammon's horn. In many cases, the lack of an appropriate specimen was due to the extensive use of ultrasonic aspiration. Most specimens contained minor and non-specific changes such as focal gliosis of the end folium or other parts of the hippocampal formation, subpial gliosis, or diffuse white matter gliosis irrespective of the presence or absence of a specific focal lesion or classic Ammon's horn sclerosis. As representative specimens of the hippocampus were not available in many cases, it was impossible to give a specific figure for the number of entirely normal samples for the whole series.

The most frequent tumour was a ganglioglioma, and all but two tumours were of low histopathological grade (table 2). Dysembryoplastic neuroepithelial tumours were present in eight patients. This entity has recently been included in the 1993 World Health Organisation (WHO) classification of CNS

Table 2 Histopathological diagnoses in 79 tumours

\begin{tabular}{lc}
\hline Diagnosis & Patients \\
No $(\%)$ \\
\hline Ganglioglioma (WHO grade I) & $29(36 \cdot 7)$ \\
Ganglioglioma (WHO grade II) & $3(3 \cdot 8)$ \\
Anaplastic ganglioglioma (WHO grade III) & $1(1 \cdot 3)$ \\
Pilocytic astrocytoma (WHO grade I) & $18(22 \cdot 7)$ \\
Astrocytoma (WHO grade II) & $6(7 \cdot 6)$ \\
Anaplastic astrocytoma (WHO Grade III) & $1(1 \cdot 3)$ \\
Oligodendroglioma (WHO grade II) & $10(12 \cdot 6)$ \\
Oligoastrocytoma (WHO grade II) & $1(1 \cdot 3)$ \\
Pleomorphic xanthoastrocytoma & $1(1 \cdot 3)$ \\
Epidermoid & $1(1 \cdot 3)$ \\
Dysembryoplastic neuroepithelial tumour & $8(10 \cdot 1)$ \\
Total & $79(100 \cdot 0)$ \\
\hline
\end{tabular}


Table 3 MRI diagnoses in 77 histopathologically verified neoplastic lesions

\begin{tabular}{|c|c|c|c|c|c|}
\hline \multirow[b]{2}{*}{ Histopathological diagnosis } & \multicolumn{5}{|c|}{ MRI diagnosis } \\
\hline & $\begin{array}{l}\text { Tumour } \\
\text { No }\end{array}$ & $\begin{array}{l}\text { Non-tumorous } \\
\text { lesion No }\end{array}$ & $\begin{array}{l}\text { "Uncertain" } \\
\text { No }\end{array}$ & $\begin{array}{l}\text { Normal } \\
\text { No }\end{array}$ & $\begin{array}{l}\text { Total } \\
\text { No }\end{array}$ \\
\hline $\begin{array}{l}\text { Ganglioglioma (WHO grade I) } \\
\text { Ganglioglioma (WHO grade II) } \\
\text { Ganglioglioma (WHO grade III) } \\
\text { Astrocytoma (WHO grade I) } \\
\text { Astrocytoma (WHO grade II) } \\
\text { Astrocytoma (WHO grade III) } \\
\text { Oligodendroglioma (WHO grade II) } \\
\text { Oligoastrocytoma (WHO grade II) } \\
\text { Pleomorphic xanthoastrocytoma } \\
\text { Dysembryoplastic neuroepithelial tumour } \\
\text { Epidermoid }\end{array}$ & $\begin{array}{r}21 \\
3 \\
1 \\
16 \\
5 \\
1 \\
10 \\
1 \\
1 \\
1 \\
7 \\
1\end{array}$ & $\begin{array}{l}\frac{1}{\overline{1}} \\
= \\
= \\
= \\
=\end{array}$ & $\begin{array}{l}\frac{5}{7} \\
\frac{7}{1} \\
= \\
\frac{1}{1}\end{array}$ & $\begin{array}{l}\frac{1}{z} \\
= \\
= \\
= \\
=\end{array}$ & $\begin{array}{r}28 \\
3 \\
1 \\
17 \\
6 \\
1 \\
10 \\
1 \\
1 \\
8 \\
1\end{array}$ \\
\hline Total & 67 & 2 & 7 & 1 & 77 \\
\hline
\end{tabular}

tumours $^{41}$ and its detailed histopathology remains to be determined. In the present series, two tumours that had been previously designated as gangliogliomas were reclassified as dysembryoplastic neuroepithelial tumours. Among non-neoplastic focal lesions, glioneuronal hamartias and cavernomas were most often found (table 1). Ammon's horn sclerosis was the only abnormality in 39 cases $(17 \cdot 2 \%)$. Correlation of focal lesions and Ammon's horn sclerosis showed that Ammon's horn sclerosis was significantly more frequent in patients without focal lesions. There was a small group, however $(25 \cdot 0 \%)$, of patients with Ammon's horn sclerosis and focal lesions ("dual pathology"). Only five patients had neither Ammon's horn sclerosis nor focal lesions. More detailed descriptions on the histopathological findings have recently been published elsewhere. ${ }^{1942}$

MRI FINDINGS

Brain MRI showed structural abnormalities in 139 of 168 cases $(82 \cdot 7 \%)$. There were signal abnormalities on MRI in 76 of the 77 histopathologically verified tumours $(98 \cdot 7 \%)$, and in 67 cases $(87 \cdot 0 \%)$ the MRI diagnosis

Table 4 MRI diagnoses in 47 histopathologically verified non-neoplastic focal lesions

\begin{tabular}{|c|c|c|c|c|c|}
\hline \multirow[b]{2}{*}{$\begin{array}{l}\text { Histopathological } \\
\text { diagnosis }\end{array}$} & \multicolumn{5}{|l|}{ MRI diagnosis } \\
\hline & $\begin{array}{l}\text { Non-tumorous } \\
\text { lesion } \\
\text { No }\end{array}$ & $\begin{array}{l}\text { Tumour } \\
\text { No }\end{array}$ & $\begin{array}{l}\text { "Uncertain" } \\
\text { No }\end{array}$ & $\begin{array}{l}\text { Normal } \\
\text { No }\end{array}$ & $\begin{array}{l}\text { Total } \\
\text { No }\end{array}$ \\
\hline Hamartia & - & 5 & 4 & 10 & 19 \\
\hline Hamartoma & $\overline{-1}$ & 3 & 2 & - & 5 \\
\hline Cavernoma & 11 & - & - & - & 11 \\
\hline AV malformation & 2 & - & 1 & - & 3 \\
\hline Necrosis & - & 1 & 1 & 1 & 3 \\
\hline Heterotopia & 3 & - & - & - & 3 \\
\hline Abscess wall & - & 1 & - & - & 1 \\
\hline Encephalitis & - & 1 & - & - & 1 \\
\hline Gliosis & 一 & 1 & - & - & $i$ \\
\hline Total & 16 & 12 & 8 & 11 & 47 \\
\hline
\end{tabular}

Table 5 MRI diagnoses in 44 patients with and without definite Ammon's horn sclerosis (AHS)

\begin{tabular}{llllll}
\hline \multicolumn{5}{l}{ MRI diagnosis } \\
\cline { 2 - 6 } $\begin{array}{l}\text { Histopathological } \\
\text { diagnosis }\end{array}$ & AHS & Tumour & “Uncertain” & Normal & Total \\
\hline AHS & No & No & No & No & No \\
No AHS & 21 & 2 & 4 & 12 & 39 \\
Total & - & - & - & 5 & 5 \\
\hline & 21 & 2 & 4 & 17 & 44 \\
\hline
\end{tabular}

AHS = Ammon's horn sclerosis. was that of a tumour. In seven tumour cases MRI showed signal abnormalities of uncertain relevance, and in one case no signal abnormality was found. In six of these eight cases, histopathological examination showed a circumscribed ganglioglioma (table 3 ).

Of 47 histopathologically verified non-neoplastic focal lesions, MRI was abnormal in 36 cases $(76 \cdot 6 \%)$. Cavernomas and heterotopias were correctly assessed in every case, whereas hamartias and hamartomas were often missed or interpreted as neoplasms. In 11 cases (23.4\%), MRI was normal. In 10 of these patients, histopathological examinations showed microscopic glioneuronal hamartias (table 4).

Of the 39 patients with histopathologically verified Ammon's horn sclerosis and no focal lesion, MRI was abnormal in 27 cases $(69 \cdot 2 \%)$. In 21 of them (53.8\%), Ammon's horn sclerosis was correctly diagnosed, whereas in two cases a tumour was suspected due to high signal intensity. All five patients with inconspicuous histopathological findings had normal MRI (table 5). Figures 2-5 are representative MRI findings from our patients.

\section{FOLLOW UP}

There was no operative or postoperative mortality. The postoperative course was complicated in 18 of 178 patients $(10.1 \%)$. In particular, six patients had deep wound infection and two had meningitis. Neurological impairment was encountered in seven patients: aphasia (one), third nerve paresis (two), hemianopsia (one), and hemiparesis (three). Deep vein thrombosis was found in two cases and peripheral nerve deficits due to inadequate positioning on the operating table in one case. Almost all of these complications resolved completely without further sequelae. Permanent morbidity occurred in three patients $(1 \cdot 7 \%)$ and included hemiparesis in two cases, and hemianopsia in one case.

Table 6 shows the outcome of patients with respect to seizure control. In total, $91.6 \%$ of the patients were seizure free or had a worthwhile improvement after surgery, whereas $\mathbf{8 . 4 \%}$ had no appreciable reduction in seizure frequency or were unchanged. We did not encounter any significant differences in seizure outcome with respect to the side of operation (right $v$ left). The most favourable 
Figure 2 Ammon's horn sclerosis: $M R I$ with $T 2$ weighted temporally $T 1$ weighted coronal image (inversion recovery) (right) shows increased signal (T2 weighted) and right hippocampal atrophy (T1 weighted) (arrows). oriented image (left) and
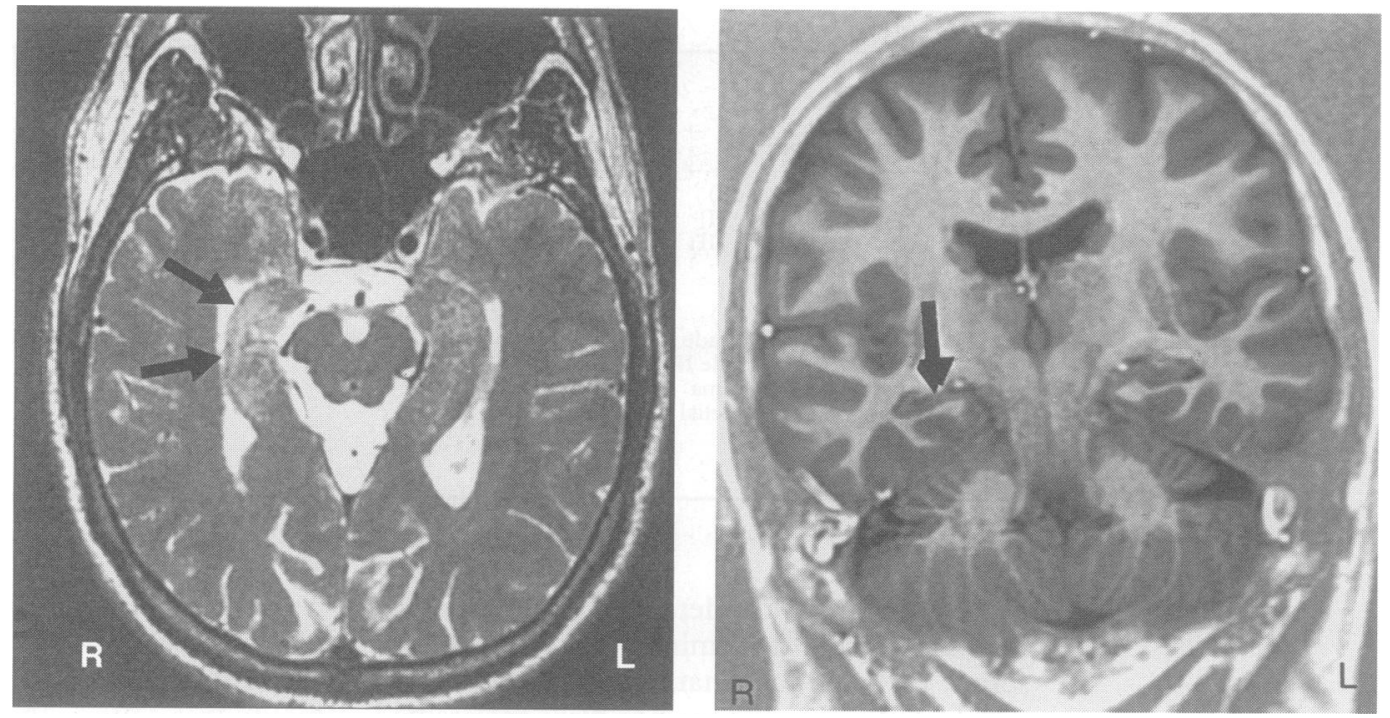

results were in patients with neoplastic lesions and Ammon's horn sclerosis. With these histopathological diagnoses, $68.5 \%$ and $66.7 \%$ of patients were seizure free. The ratio of seizure free patients with non-neoplastic focal lesions was somewhat lower $(54.0 \%)$. These differences were statistically significant $(P<0.05)$. None of the five patients in whom there were no specific histopathological findings became seizure free postoperatively (table 7). The differences in seizure outcome between patients without specific histopathological alterations and those with the diagnosis of a focal lesion or Ammon's horn sclerosis were highly significant $(P<0.001)$.

\section{Discussion}

The surgical management of epilepsy involves the identification of the epileptogenic cortex

Figure 3 Cavernoma. There is a right temporomesial lesion with central hyperintensity and peripheral signal void typical for cavernoma on axial $T 1$ weighted $M R I$. Note enlarged tip of inferior horn.

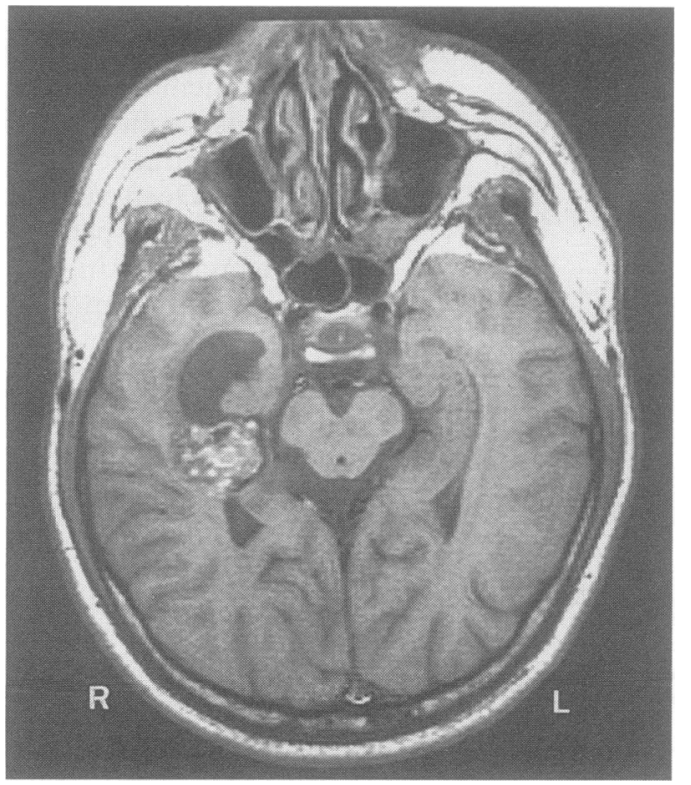

and its excision as completely as possible. ${ }^{3643}$ Despite complex diagnostic tools the definition of the epileptogenic area remains hypothetical. It is generally accepted, however, that structural abnormalities play a significant part in epileptogenesis and that altered brain has to be removed completely to achieve seizure control. Brain MRI has proved to be highly sensitive both for detection and localisation of structural lesions. ${ }^{31528323844-47}$ This study of 178 patients treated surgically for temporal lobe epilepsy was designed to evaluate the sensitivity and specificity of MRI for identifying structural abnormalities and to define the relevance of histopathological findings with respect to seizure control.

In our series, histopathological examination showed definite structural abnormalities in 173 of 178 specimens $(97 \cdot 2 \%)$. Forty nine patients who did not show a focal lesion and whom histopathological findings did not allow definite conclusions as to the presence or absence of Ammon's horn sclerosis were excluded from the total series of patients operated on during the respective period. Neoplastic lesions occurred most often $(44.4 \%)$, and all but two tumours were histopathologically benign. Among non-neoplastic focal lesions $(30.9 \%)$, hamartias and cavernomas were predominant. The relatively low rate of definite Ammon's horn sclerosis $(21.9 \%)$ reflects the fact that many specimens submitted for pathological evaluation consisted only of small tissue fragments that did not allow a reliable identification of the different segments of Ammon's horn. In many cases the lack of an appropriate specimen was due to the extensive use of ultrasonic aspiration. Regarding only specimens in which the hippocampal formation was well preserved ( $n=72$ ), $72 \cdot 2 \%$ showed Ammon's horn sclerosis. This number includes coincidence of Ammon's horn sclerosis with focal lesions as a dual pathology (25.0\% of focal lesions). Thus Ammon's horn sclerosis represents the most 
Figure 4 Glioneuronal hamartia. MRI with four coronal T2 weighted slices shows a partly cystic lesion with pronounced cortical and subcortical

hyperintensity in the right mesial temporal lobe.

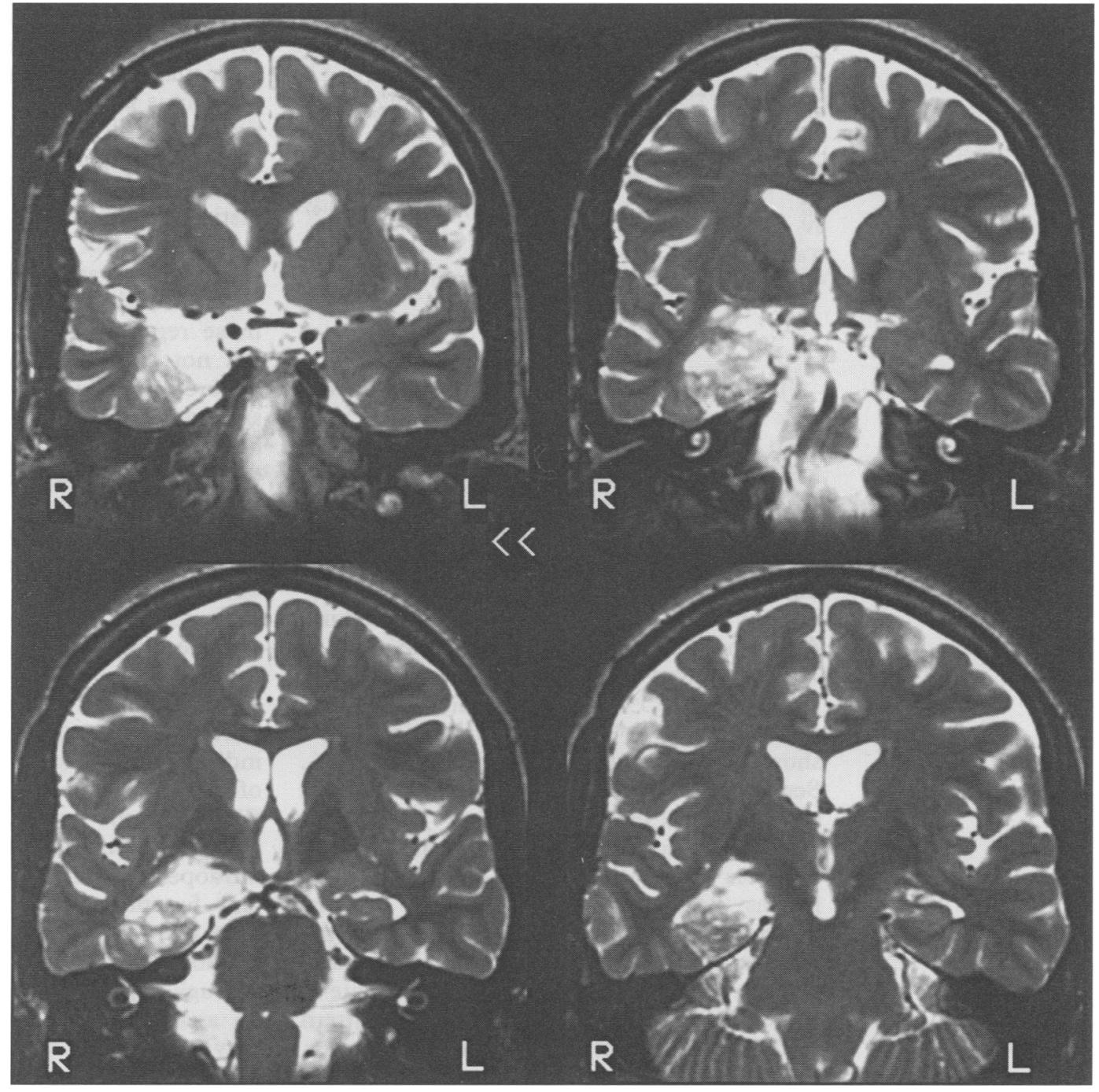

important structural abnormality in temporal lobe epilepsy, whereas low grade gliomas and non-neoplastic focal lesions are found with a lower frequency.122324264748 The fact that almost all lesions found in our patients were histopathologically benign corresponds well with the usually long history of seizures, which was similar in patients with and without lesions, although the age at time of surgery and the age at the first onset of seizures was significantly lower in patients with focal lesions than in those without focal lesions.
Figure 5 Ganglioglioma (WHO grade I). Proton density (left) and T2 weighted (right) axial MRI illustrate a minimally space occupying lesion of the left uncus with pronounced hyperintensity in both images.

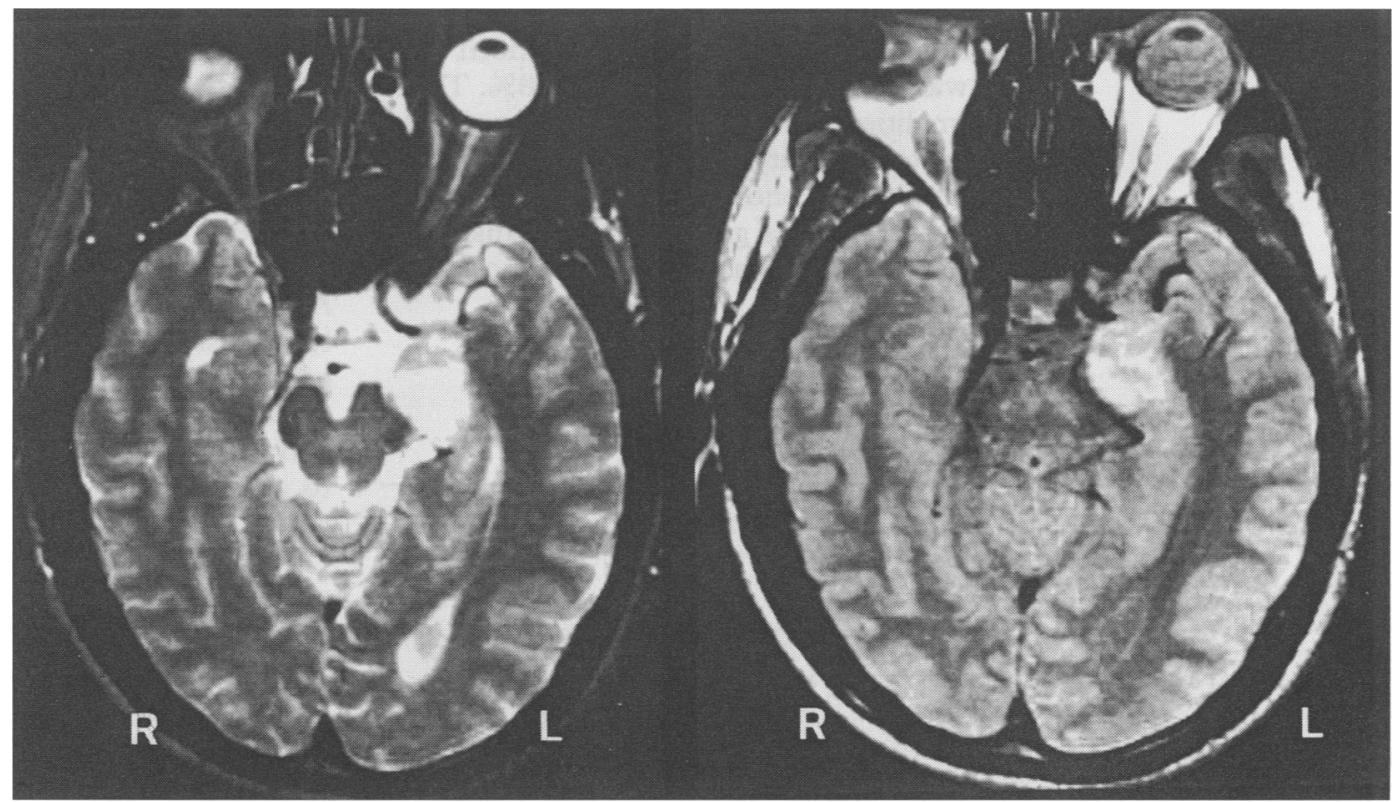


Table 6 Seizure outcome in 167 patients divided into four classes related to the operation side

\begin{tabular}{llrr}
\hline & \multicolumn{3}{l}{ Patients } \\
\cline { 2 - 4 } $\begin{array}{l}\text { Outcome } \\
\text { class }\end{array}$ & Right & Left & Total \\
& No $(\%)$ & No $(\%)$ & No $(\%)$ \\
\hline I & $59(59 \cdot 6)$ & $44(64 \cdot 7)$ & $103(61 \cdot 7)$ \\
II & $16(16 \cdot 2)$ & $10(14 \cdot 7)$ & $26(15 \cdot 5)$ \\
III & $15(15 \cdot 1)$ & $9(13 \cdot 2)$ & $24(14 \cdot 4)$ \\
IV & $9(9 \cdot 1)$ & $5(7 \cdot 4)$ & $14(8 \cdot 4)$ \\
Total & $99(100 \cdot 0)$ & $68(100 \cdot 0)$ & $167(100 \cdot 0)$ \\
\hline
\end{tabular}

The high anatomical resolution and the lack of artifacts from overlying bone have been stressed as advantages of MRI over CT; MRI is more sensitive in detecting small structural lesions than CT with the exception of small areas of calcification for which CT is more sensitive. ${ }^{1346}$ 49-52 In view of these findings, MRI is used in most institutions including our own as the initial imaging procedure. Abnormalities are found on MRI in $40 \%$ to $70 \%$ of patients with temporal lobe epilepsy, ${ }^{28} 48$ and $20 \%$ to $25 \%$ of these abnormalities are missed by CT. ${ }^{460-52}$ In our series, MRI showed structural abnormalities in $82.7 \%$. Sensitivity and specificity of MRI were highest in tumours $(98 \cdot 7 \%$ and $87 \cdot 0 \%)$. In nontumorous lesions, MRI was abnormal in 36 of 47 cases $(76.6 \%)$; however, only 16 of these lesions $(34.0 \%)$ were recognised to be nontumorous. It is remarkable that none of the hamartias and hamartomas were recognised as lesions by MRI. This may be in part due to the small size and variable distribution pattern of these lesions. In some patients, however, the glioneuronal malformations were of considerable size and were therefore classified as probable neoplasms based on MRI criteria. Special attention has been paid to the sensitivity of MRI for detection of Ammon's horn sclerosis. By contrast with Sperling et al, ${ }^{38}$ who did not find MRI abnormalities in patients with Ammon's horn sclerosis, others have shown abnormal signals in $50 \%$ to $80 \% .^{21624}$ Even severity of pathological changes seems to correlate with the relative intensity of the abnormal signals. ${ }^{16} 2021$ In our series, MRI was abnormal in $69.2 \%$ and Ammon's horn sclerosis was correctly diagnosed in $53.8 \%$. These abnormalities were best seen on T2 weighted and proton density weighted images in the coronal plane. Abnormal high intensity signal in two of our cases gave rise to the diagnosis of a tumour. In 12 cases, MRI was inconspic-

Table 7 Seizure outcome related to histopathological diagnoses

\begin{tabular}{|c|c|c|c|c|c|}
\hline \multirow[b]{2}{*}{$\begin{array}{l}\text { Outcome } \\
\text { class }\end{array}$} & \multicolumn{5}{|c|}{ Histopathological diagnosis } \\
\hline & $\begin{array}{l}\text { Neoplasm } \\
\text { No (\%) }\end{array}$ & $\begin{array}{l}\text { Non-neoplastic } \\
\text { lesion } \\
\text { No (\%) }\end{array}$ & $\begin{array}{l}\text { Ammon's horn } \\
\text { sclerosis } \\
\text { No (\%) }\end{array}$ & $\begin{array}{l}\text { Normal } \\
\text { No (\%) }\end{array}$ & $\begin{array}{l}\text { Total } \\
\text { No (\%) }\end{array}$ \\
\hline $\begin{array}{l}\text { I } \\
\text { II } \\
\text { IV }\end{array}$ & $\begin{array}{c}50(68 \cdot 5) \\
13(17 \cdot 8) \\
9(12 \cdot 3) \\
1(1 \cdot 4)\end{array}$ & $\begin{array}{r}27(54 \cdot 0) \\
7(14 \cdot 0) \\
8(16 \cdot 0) \\
8(16 \cdot 0)\end{array}$ & $\begin{aligned} & 26(66 \cdot 7) \\
& 6(15 \cdot 4) \\
& 5(12 \cdot 8) \\
& 2(5 \cdot 1)\end{aligned}$ & $\begin{array}{l}-(-) \\
-(-) \\
2(40 \cdot 0) \\
3(60 \cdot 0)\end{array}$ & $\begin{array}{c}103(61 \cdot 7) \\
26(15 \cdot 5) \\
24(14 \cdot 4) \\
14(8 \cdot 4)\end{array}$ \\
\hline Total & $73(100 \cdot 0)$ & $50(100 \cdot 0)$ & $39(100 \cdot 0)$ & $5(100 \cdot 0)$ & $167(100 \cdot 0)$ \\
\hline
\end{tabular}

uous; however, in all of these cases the quality of the images was unsatisfactory. Volumetric or signalometric measurements of the hippocampus may represent a valuable diagnostic tool for demonstration and quantification of hippocampal sclerosis. ${ }^{34554}$ These measurements have not been performed at our institution so far.

With respect to seizure outcome, about $92 \%$ of our patients benefited from surgery. These results correspond favourably with those reported from other centres. ${ }^{30} 55-57$ We did not encounter significant differences in seizure outcome comparing the side of surgery (right $v$ left). Patients with Ammon's horn sclerosis or focal lesions had a significantly better outcome than patients without specific histopathological findings. It seems to be remarkable that none of the patients in whom specific structural changes were absent became seizure free postoperatively. This indicates that histopathological evaluation provides prognostically relevant information.

Controversy exists with respect to the surgical approach in temporal lobe epilepsy and intraoperative techniques. At some centres the indication for surgery is based on the location of interictal events as determined by scalp EEG, and the resection is carried out under local anaesthesia and tailored to the results of intraoperative electrocorticography (ECoG) and functional mapping. ${ }^{58-60}$ Other centres base the selection of surgical candidates on extraoperative recordings of seizure onset through depth electrodes. This is followed by an anatomically standardised resection that may be either a standard anterior temporal lobectomy with resection of both mesial and lateral structures ${ }^{61}$ or a more limited resection such as a selective amygdalohippocampectomy ${ }^{40}$ In the present series, we have combined features of these two opposite approaches. The definition of the epileptogenic area was based on extraoperative evaluation of the seizure focus. In earlier non-lesional cases, resection of lateral structures was a standardised removal of the anterior 4 to $5 \mathrm{~cm}$ of the temporal lobe. More recently, we have limited and individualised the lateral resections according to the patient's EEG and functional localisation results. In our experience, combined subdural and hippocampal depth electrodes have proved to be valuable to distinguish the foci of mesial and lateral seizures. Obviously, no single approach to resective surgery is suitable for all patients. Although in most cases the location of a structural lesion roughly indicates the epileptogenic area the relation is not absolute and the extent of resection should be tailored to extraoperative electrocorticographic findings to include the cortical zones of seizure origin and maximal interictal epileptiform activity.

In conclusion, detailed histopathological evaluation of temporal lobe epilepsies emphasises the role of structural abnormalities for epileptogenesis and allows important prognostic conclusions. Magnetic resonance imaging is reliable in identifying tumorous lesions. Imaging techniques need further improvement, 
however, for detection of non-tumorous focal lesions and Ammon's horn sclerosis. Further improvement of morphological and functional imaging techniques and refined electrophysiological examinations can be expected to allow a more precise preoperative definition of the epileptogenic area. This will further facilitate the use of tailored resections instead of classic standardised operations.

We thank DK Böker and W Entzian for their contribution to this study.

1 Keranen T, Reikkinen P. Severe epilepsy: diagnostic and epidemiological aspects. Acta Neurol Scand 1988;78 (suppl):7-14.

2 Hauser WA. The natural history of temporal lobe epilepsy. In: Lüders HO, ed. Epilepsy surgery. New York: Raven Press, 1992:133-41.

3 Bergen D, Bleck T, Ramsey R, et al. Magnetic resonance imaging as a sensitive and specific predictor of neoplasms removed for intractable epilepsy. Epilepsia 1989 30:318-21.

4 Boon PA, Williamson PD, Fried I, et al. Intracranial, intraaxial, space-occupying lesions in patients with intractable partial seizures: an anatomo-clinical, neuropsychological, and surgical correlation. Epilepsia 1991;32:467-76.

5 Cascino DG. Epilepsy and brain tumors: implications for treatment. Epilepsia 1990;31(suppl):37-44.

6 Cavanagh JB. On certain small tumours encountered in the temporal lobe. Brain 1958;81:389-405.

7 Daumas-Duport C, Scheithauer BW, Chodkiewiez JP, et al. Dysembrioblastic neuroepithelial tumor: a surgically curable tumor of young patients with intractable partial seizures. Neurosurgery 1980;23:545-56.

8 Falconer MA, Serafetinides EA, Corsellis JAN. Etiology and pathogenesis of temporal lobe epilepsy. Arch Neurol 1964;10:233-48.

9 Ketz E: Brain tumours and epilepsy. In: Vinken and Bruyn, eds. Handbook of clinical neurology. Vol 16 , Amsterdam: Elsevier 1974:254-69.

10 Rasmussen T. Surgery of epilepsy associated with brain tumors. In: Purpura DP, Penry JK, Walter RD, eds. Advances in neurology. Vol 8. New York: Raven Press, 1975:227-39.

11 Rich KM, Goldring S, Gado M. Computed tomography in chronic seizure disorder caused by glioma. Arch Neurol 1985;42:26-7.

12 Spencer DD, Spencer SS, Mattson RH, Williamson PD. Intracerebral masses in patients with intractable Intracerebral masses in patients
epilepsy. Neurology $1984 ; 34: 432-6$.

13 Tampieri D, Moumdjian R, Melanson D, et al. Intracerebral gangliogliomas in patients with partial complex seizures. CT and MR Imaging findings. $A f N R$ Am $\mathcal{F}$ Neuroradiol 1991;12:749-55.

14 Armstrong DD. The neuropathology of temporal lobe epilepsy. F Neuropathol Exp Neurol 1993;52:433-43.

15 Dowd CF, Dillon WP, Barbaro NM, et al. Magnetic resonance of intractable complex partial seizures: pathologic and electro-encephalographic correlation. Epilepsia 1991;32:454-9.

16 Kuzniecky R, de la Sayete V, Ethier R, et al. Magnetic resonance imaging in temporal lobe epilepsy: pathological onance imaging in temporal lobe epileps:

17 Smith A, Weinstein M, Quencer $\mathrm{R}$, et al. Association of heterotopic grey matter with seizures: MR imaging. Radiology 1988;168:195-8.

18 Vinters HV, Armstrong DL, Babb TL, et al. The neuropathology of human symptomatic epilepsy. In: Engel $\mathrm{J}$, ed. Surgical treatment of the epilepsies. 2nd ed. New York: Raven Press, 1993:593-608.

19 Wolf HK, Campos MG, Zentner J, et al. Surgical pathology of temporal lobe epilepsy. Experience with 216 cases. $₹$ Neuropathol Exp Neurol 1993;52:499-506.

20 Berkovic SF, Andermann F, Oliver A, et al. Hippocampal sclerosis in temporal lobe epilepsy demonstrated by magnetic resonance imaging. Ann Neurol 1991;29: 175-82.

21 Bronen RA, Cheung G, Charles JT, et al. Imaging findings in hippocampal sclerosis: correlation with pathology. in hippocampal sclerosis: correlation with

22 Cascino DG, Jack CR, Parisi JE, et al. Magnetic resonance imaging-based volume studies in temporal lobe epilepsy: pathological correlations. Ann Neurol 1991;30:31-6.

23 Falconer MA. Mesial temporal (Ammon's horn) sclerosis as a common cause of epilepsy: etiology, treatment, and prevention Lancet 1974;2:767-70.

24 Gates JR, Cruz-Rodriguez R. Mesial temporal sclerosis: pathogenesis, diagnosis, and treatment. Epilepsia 1990; 318(suppl):55-66.

25 Dam AM. Epilepsy and neuron loss in the hippocampus. Epilepsia 1980;21:617-29.

26 Drake J, Hoffmann HJ, Kobayashi J, et al. Surgical management of children with temporal lobe epilepsy and mass lesions. Neurosurgery 1987;21:792-7.

27 Fried I, Kim JH, Spencer DD. Hippocampal pathology in patients with intractable seizures and temporal lobe masses. F Neurosurg 1992;76:735-40.

28 Brooks BS, King DW, Gammal TE, et al. MR Imaging in patients with intractable complex partial epileptic seizures. AfNR Am ₹ Neuroradiol 1990;11:93-9.
29 Elster AD, Mirza W. MR imaging in chronic partial epilepsy: role of contrast enhancement. $A \mathcal{F N R} A m \mathcal{F}$ Neuroradiol 1991;12:165-70.

30 Engel J, Van Ness P, Rasmussen TB, et al. Outcome with respect to epileptic seizures. In: Engel J, ed. Surgical treatment of the epilepsies. 2nd ed. New York: Raven Press, 1993:609-21.

31 Feindel W, Robitaille Y, Tampieri D, et al. Electroencephalographic, magnetic resonance imaging and pathology in patients surgically treated for temporal lobe epilepsy. Can F Neurol Sci 1991;18:577-9.

32 Jabbari B, Gunderson CH, Wippold F, et al. Magnetic resonance imaging in partial complex epilepsy. Arch Neurol 1986;43:869-72.

33 Kilpatrick CJ, Tress BM, O'Donnell Ch, et al. Magnetic resonance imaging and late-onset epilepsy. Epilepsia 1991;32:358-64.

34 Lencz T, McCarthy G, Bronen RA, et al. Quantitative magnetic resonance imaging in temporal lobe epilepsy: relationship to neuropathology and neur

35 Lesser RP, Modic MT, Weinstein MA, et al. Magnetic resonance imaging ( $1: 5$ Tesla) in patients with intractable focal seizures. Arch Neurol 1986;43:367-71.

36 McLachlan RS, Nicholson RL, Black S, et al. Nuclea magnetic resonance imaging, a new approach to the investigation of refractory temporal lobe epilepsy. Epilepsia 1985;26:555-62.

37 Sharbrough F, Jack C, Cascino G. Presurgical quantitative magnetic resonance based on hippocampal volume measurements in patients undergoing temporal lobectomie for medically intractable seizures. Epilepsia 1989;30:675.

38 Sperling MR, Wilson G, Engel J, et al. Magnetic resonance imaging in intractable partial epilepsy: correlative imaging in intractable partial

39 Grünwald F, Menzel C, Pavics L, et al. Ictal and interictal brain SPECT imaging in epilepsy using technetium99m-ECD. F Nucl Med 1994 (in press).

40 Wieser HG, Yasargil MG. Selective amygdalhippocampectomy as a surgical treatment of mesiobasal limbic epilepsy. Surg Neurol 1982;16:445-456.

41 Kleihues P, Burger PC, Scheithauer BW. Histological typing of tumors of the central nervous system. Berlin Springer, 1993

42 Wolf HK, Wiestler OD. Surgical pathology of chronic epileptic seizure disorders. Brain Pathol 1993;3:371-80.

43 Lüders H, Engel J, Munari C. General principles. In: Engel J, ed. Surgical treatment of the epilepsies. 2nd ed. New York: Raven Press 1993:137-53.

44 Heinz ER, Crain BJ, Radtke RA, et al. MR imaging in patients with temporal lobe seizures: correlation of patients with temporal lobe seizures: correlation of results with patho

45 Ryvlin P, Garcia-Larrea L, Philippon B, et al. High signal intensity on T2-weighted MRI correlates with hypoperfusion in temporal lobe epilepsy. Epilepsia 1992;33

46 Theodore WH, Dorwart R, Holmes M, et al. Neuroimaging in refractory partial seizures: comparison of PET, CT, and MRI. Neurology 1986;36:750-9.

47 Triulzi F, Franceschi M, Fazio F, Del Maschio A. Non refractory temporal lobe epilepsy: 1,5-T MR imaging. Radiology 1988;166:181-5.

48 Turner DA, Wyler AT. Temporal lobectomy for epilepsy: mesial temporal herniation as an operative and prognostic finding. Epilepsia 1981;22:623-9.

49 Holland BA, Kucharcyzk W, Brant-Zawadzki M, et al. MR imaging calcified intracranial lesions. Radiology 1985; 157:353-6.

50 Latack JT, Abou-Khalil B, Siegel GJ, et al. Patients with partial seizures: evaluation by MR, CT, and PET imaging. Radiology 1986;159:159-63.

51 Ormson MJ, Kispert DB, Scharbrough FW, et al. Cryptic structural lesions in refractory partial epilepsy: MR imaging and CT studies. Radiology 1986;160:215-9.

52 Schörner W, Meencke HJ, Felix R. Temporal-lobe epilepsy: comparation of CT and MR imaging. $A f R A m$ f Neuroradiol 1987;149:1231-9.

53 Cendes F, Andermann F, Gloor P, et al. Atrophy of mesial structures in patients with temporal lobe epilepsy: cause or consequence of repeated seizures? Ann Neurol 1993; 34:795-801.

54 Jack CR, Sherbrough FW, Twomey CK, et al. Temporal lobe seizures: lateralization with MR volume measurements of the hippocampal formation. Radiology 1990; ments of th:423-9.

55 Duncan JS, Sager HJ. Seizure characteristics, pathology and outcome after temporal lobectomy. Neurology 1987 37:405-9.

56 Elwes RDC, Dunn G, Binnie CD, Polhey CE. Outcome following resective surgery for temporal lobe epilepsy: a prospective follow-up study of 102 consecutive cases. f Neurol Neurosurg Psychiatry 1991;54:949-52.

57 Olivier A: Relevance of removal of limbic structures in surgery for temporal lobe epilepsy. Can 7 Neurol $\mathrm{Sci}_{\mathrm{i}}$ 1991;18:628-35.

58 Bronen RA. Temporal lobectomy. In: Spencer SS, Spencer DD, eds. Surgery for epilepsy. Boston: Blackwell Scientific, 1991:103-49.

59 Ojemann GA. Surgical therapy for medically interactable epilepsy. F Neurosurg 1987;66:489-99.

60 Penfield W, Jasper HH. Epilepsy and the functional anatomy of the human brain. Boston: Little-Brown, 1954.

61 Falconer M. Anterior temporal lobectomy for epilepsy. In Logue V, ed. Neurosurgery, 2nd ed. Operative surgery. Vol 14. London: Butterworths, 1971:142-9. 